\title{
ANÁLISE HISTÓRICA DA EDUCAÇÃO FÍSICA DO IFPB: DO SURGIMENTO NA ESCOLA INDUSTRIAL DE JOÃO PESSOA (1945) AINFLUÊNCIA DOS ESPORTES NA DÉCADA DE 70
}

\section{Maria Josély de Figueirêdo Gomes}

Professora do Curso de Turismo; Lazer e Qualidade de Vida do IFRN, professora

Educação Física, Especialização em Treinamento Desportivo (UFPB), Mestra em Educação (UFPB) e Doutora em Actividad Física para la Salud (Universidad de Granada-

Espanha). Jogranada2004@yahoo.com.br

\section{RESUMO}

O presente estudo foi realizado como parte da dissertação de Mestrado e Tese de Doutorado da referida autora. Este trabalho faz parte de um trabalho mais amplo, que foi fazer um breve histórico da Educação Física do IFPB, desde seu início (1945) até o início do século XXI (2003). Para este trabalho específico foi realizado a análise histórica de 1945 até a década de 70. Foi realizado um levantamento documental no acervo do IFPB, juntamente com entrevista semi-estruturada com 6 professores. Como conclusão pode-se dizer que é de grande importância conhecer o percurso histórico de uma disciplina em uma instituição, podendo servir como referencia na discussão para adaptação e ou reconstrução do currículo escolar.

PALAVRAS-CHAVE: Educação Física, Ensino Profissionalizante, IFPB.
ANÁLISIS HISTÓRICO DE LA EDUCACIÓN FÍSICA DEL IFPB: DE LA APARICIÓN EN LA ESCUELA INDUSTRIAL DE JOÃO PESSOA (1945) A LA INFLUENCIA DE LOS DEPORTES EM LA DÉCADA DE LOS 70.

\section{RESUMEN}

El presente estudio fue realizado como parte de la disertación de Master e Tesi Doctoral de la referida autora. Este trabajo hace parte de un trabajo más amplio, que fue construir un análisis histórico de la Educación Física del IFPB, desde su inicio (1945) hasta inicio del siglo XXI (2003). Para este trabajo específico fue realizada la análisis histórica de 1945 hasta la década de los 70. Fue construido una recorrida de datos documental en el acervo del IFPB, como también entrevista semi-estructurada con 6 profesores. Como conclusión se puede decir que es de gran importancia conocer el camino histórico de una asignatura en una institución, pues puede servir como referencia en la discusión para la adaptación y o reconstrucción del currículo en la escuela.

PALABRAS-LLAVE: Educación Física, Enseñanza Professional, IFPB. 


\section{ANÁLISE HISTÓRICA DA EDUCAÇÃO FÍSICA DO IFPB, DO SURGIMENTO NA ESCOLA INDUSTRIAL DE JOÃO PESSOA (1945) A INFLUÊNCIA DOS ESPORTES NA DÉCADA DE 70}

\section{INTRODUÇÃO}

Uma das primeiras manifestações da Educação Física Escola (EFE) no Brasil foi no ano de 1854, foi feita a Reforma Couto Ferraz, a qual tornou obrigatória a Educação Física nas escolas do município da Corte, apesar de todas as dificuldades, pela não aceitação dos pais, que não aceitavam ver os filhos envolvidos com atividades que não fossem intelectuais. Naquela época, a Educação Física estava vinculada às instituições militares, à educação do físico, almejando a ordem e o progresso. Era importante formar indivíduos fortes e saudáveis, que pudessem defender a pátria e seus ideais.

No ano de 1882, Rui Barbosa defendeu a inclusão da ginástica nas escolas e a equiparação dos professores de ginástica aos das outras disciplinas.

Em 1937, na elaboração da Constituição, faz-se a primeira referência explícita à Educação Física em textos Constitucionais Federais, incluindo-a no currículo como prática educativa obrigatória (e não como disciplina curricular). Havia também um artigo naquela Constituição que citava o adestramento físico como maneira de preparar a juventude para a defesa da nação e para o cumprimento dos deveres com a economia.

A Educação Física como componente curricular nas Instituições Públicas Federais de Educação Profissional, neste caso específico, o IFPB teve seu lugar de prestígio no interior destas instituições, uma vez que era a disciplina, do núcleo comum, com maiores recursos com relação a espaço físico e material didático-pedagógico, como também a disciplina que mais realizava atividades extra-classe apoiadas pela instituição.

Também foi possível constatar que o IFPB, como Instituição Federal de ensino, seguiu em toda história da disciplina Educação Física as instruções das instâncias superiores de educação do Governo Federal, sem questioná-las. Sabe-se que, em muitos momentos, usou-se a Educação Física politicamente, ora para desviar a atenção da população de alguns fatos, ora para formar atletas para divulgação do país internacionalmente.

O objetivo deste trabalho é descrever a trajetória histórico-crítica da disciplina Educação Física no interior do agora IFPB, desde o seu início (1945) até a década de 70. Esta pesquisa é um recorte de um trabalho mais amplo, que fez parte da construção de uma dissertação de Mestrado e Tese de Doutorado da referida autora.

O trabalho foi desenvolvido na perspectiva qualitativa e utilizou as técnicas do levantamento bibliográfico e documental. Os documentos disponíveis, embora só a partir de 1960, eram bastante significativos, a saber: relatórios, programas da disciplina, conteúdos planejados para serem trabalhados durante atividades curriculares e extracurriculares, propostas pedagógicas da disciplina, planos de curso, solicitações para melhoramento da estrutura física da Coordenação, enfim, dados da Educação Física na vida da escola. Tais documentos foram encontrados na Coordenação de Educação Física (CEF), Coordenação Pedagógica, Coordenação de Registros Escolares (CORE) e arquivo. A técnica utilizada para análise do conteúdo dos documentos foi análise por categorias. 
Paralelamente à análise documental foram realizadas entrevistas semi-estruturadas com seis professores/as, dentre os quais cinco aposentados e um da ativa. Dos seis entrevistados, cinco atuaram a partir de 1960. Para entendermos o que aconteceu com a Educação Física do IFPB antes de 1960, conseguimos entrevistar o professor que iniciou esta prática pedagógica no então Ginásio Industrial de João Pessoa, segundo ele, em 1945. Foram realizadas, também, entrevistas informais com quatro dentre os doze professores da ativa em que se discutiram as legislações, as metodologias utilizadas, os conteúdos das aulas, entre outras particularidades da disciplina na década de 70. Estas entrevistas tiveram como objetivo identificar o processo do ensino da Educação Física dentro do IFPB, em relação aos seguintes aspectos: o prestígio da Educação Física na instituição, no olhar dos alunos; os objetivos pedagógicos, as metodologias utilizadas, o lugar ocupado pela Educação Física no currículo; e, enfim, a percepção de cada professor entrevistado sobre a Educação Física dentro da escola. $\mathrm{Na}$ análise dos conteúdos dos corpus das entrevistas utilizamos a técnica da categorização.

O levantamento documental e as entrevistas semi-estruturadas proporcionaram um material rico para esta reconstrução histórica, favorecendo um entendimento mais crítico da história da Educação Física escolar no IFPB.

\section{SURGIMENTO DA EDUCAÇÃO FÍSICA NA ESCOLA INDUSTRIAL DE JOÃO PESSOA}

A Educação Física foi oferecida como prática educativa no ano de 1945, na então Escola Industrial de João Pessoa (EIJP), pelo Professor Walter Rabelo, licenciado em Educação Física no Rio de Janeiro, na $1^{\text {a }}$ turma da Escola Nacional de Educação Física, nomeado pelo então Diretor Carlos Leonardo Arcoverde. Até então, as Escolas Industriais no Brasil ofereciam Educação Física, entretanto, esta disciplina não era ministrada por professores formados. Uma nova instrução nacional do Governo Federal, através do Ministério da Educação, postulava todas as Escolas Industriais tivessem professores de Educação Física devidamente habilitados.

O professor Walter Rabelo começou a lecionar Educação Física na Escola Industrial de João Pessoa, que, naquele momento, tinha sua sede no bairro das Trincheiras, centro da cidade. Sem espaço físico adequado para prática desta atividade pedagógica, o professor Walter conseguiu fazer um acordo com o Clube Cabo Branco, que na época tinha sede no Centro da Cidade de João Pessoa, próxima à Escola Industrial, onde se realizaram as primeiras aulas da referida disciplina. Os alunos, de então, eram selecionados pela altura e idade, sendo aqueles com menos de 18 anos obrigados a comparecer às aulas de Educação Física. O Departamento médico e biométrico foi estruturado sob a responsabilidade do professor Walter Rabelo e, ali, todos os alunos eram submetidos a exames específicos, inclusive exame odontológico:

"Consegui do diretor da Escola Dr. Carlos uma equipagem de primeira categoria para o departamento médico e biométrico" (Professor aposentado - 1).

A instrução das aulas de Educação Física tinha como prioridade orientar os jovens no modo de atuarem no cotidiano extra-escolar com relação à saúde, à alimentação e ainda, formas de evitar vícios. Depois de definidas as turmas homogeneamente, tendo em vista peso, altura e idade, iniciaram-se as aulas em horários previamente estabelecidos. 
A clientela da Escola era quase em sua totalidade de baixa renda. Talvez por isso, e para estimular a freqüência da disciplina, os alunos eram condicionados a só tomarem o café da manhã após a prática da Educação Física.

Ainda naquela data, a Escola Industrial participa da $1^{\text {a }}$ Olimpíada Estudantil da Paraíba, graças ao esforço do professor Walter, que impôs ${ }^{1}$ a participação da Escola Industrial, já que naquele instante ainda havia um preconceito quanto à indisciplina dos alunos por serem de classe social pobre. A Escola se saiu muito bem e participou de jogos nos clubes da cidade:

"Eu então, também, como professor fui nomeado para o colégio estadual na época. Impus a condição da escola tomar parte nas olimpíadas e a escola tomou parte nas primeiras olimpíadas estudantis naquela época" (Professor aposentado - 1).

As aulas de Educação Física no período de 1945-1959, quando ministradas, apenas, pelo Professor Walter obedeciam a um plano semanal baseado nos ensinamentos da Escola Nacional de Educação Física do Rio de Janeiro. A carga horária era de 3 aulas semanais e a presença do alunado era maciça. As aulas de exercícios físicos eram baseadas no Método Francês ${ }^{2}$ exigência, segundo professor Walter, do Ministério da Educação e Cultura (MEC). Nos primeiros meses, as aulas eram basicamente com movimentos de ginástica. Passada a $1^{\text {a }}$ etapa, os alunos eram então selecionados para as práticas de esporte, tais como: basquete, futebol, vôlei, atletismo. Todos os alunos eram obrigados, após a prática de Educação Física ou desportiva, a tomar banho.

A Educação Física nesse período, apesar de ser uma prática educativa (e não disciplina), era obrigatória. Por sugestão do professor Walter à Direção daquela escola, havia a chamada, com os registros das atividades e o aluno tinha que comparecer.

"Por sugestão nossa o Diretor determinou que fosse obrigatória. Fazia chamada com o pessoal, tinha que comparecer" (Professor aposentado - 1).

Nesta época, na Escola Industrial de João Pessoa, a Educação Física, segundo depoimento do professor Walter, era importante porque colaborava para melhorar o comportamento dos alunos, estimulava os jovens à pratica de esportes e oportunizava vivências sociabilizantes nos clubes, em outros espaços da sociedade, como também preparava os jovens para enfrentarem as lutas da vida.

No período de 1945 a 1959, não só a Escola Industrial de João Pessoa, mas toda a Educação Física escolar no Brasil sofria uma influência "médico-higienicista onde a ginástica era o conteúdo das aulas e tinha a função de assegurar a saúde e o vigor dos corpos, aumentando a reprodução e longevidade dos indivíduos, como também colaborar na formação moral" (Castellani, 1988, p. 42 apud Mello e Bracht, 1992). Tratava-se de uma tentativa simplista de se resolverem os problemas da saúde pública na escola, através da Educação Física.

\footnotetext{
${ }^{1}$ O professor Walter trabalhava também como professor no colégio estadual e gozava de prestígio nas Instituições em que trabalhava.

${ }^{2}$ O Método Francês para Betti (1991 apud SILVA, 1994) se caracterizava pela formalidade, rigidez e por situar-se no polo do trabalho em oposição aos aspectos lúdicos do jogo.
} 
Sob o comando do professor Walter Rabelo, porém, uma mudança é percebida: a abrangência anterior, médico-higienicista perde terreno para o treino desportivo e para os jogos esportivos, que, gradativamente, vão-se tornando, senão conteúdo único, certamente predominante. Segundo (SOARES, 1996, p. 9) "os treinos esportivos são ditados mais pela fisiologia agora já acrescida do item esforço, do que pela pedagogia”. Ao final da década de 50, ginástica vai perdendo seu posto de conteúdo principal para o desporto, em vista das mudanças econômicas e políticas ocorridas no Brasil, já que suas características se enquadram melhor ao modelo mais internacionalizado de desenvolvimento brasileiro.

\section{DÉCADA DE 60: AFIRMAÇÃO DA EDUCAÇÃO FÍSICA DA ESCOLA INDUSTRIAL DE JOÃO PESSOA}

Na década de 60, ocorreram dois novos fatos. Em 1961, o professor Walter conseguiu um professor auxiliar para Educação Física, o professor Braúlio dos Santos. No decorrer dessa década, a partir de 1962, houve a transição do prédio da Escola Industrial das Trincheiras para a Avenida $1^{\circ}$ de maio em Jaguaribe, embora a nova sede não estivesse totalmente concluída.

Essa nova sede não dispunha de nenhum espaço para a prática da Educação Física. Havia um espaço grande, mas sem condições para prática de atividades. Hoje, nesse mesmo espaço, estão o campo de futebol e a pista de atletismo.

Quando iniciou as atividades na EIJP, o professor Bráulio assumiu o comando da Educação Física, já que o professor Walter estava desempenhando outras funções na Escola.

O professor Bráulio, junto com os alunos, limparam o terreno para fazer uma pista de 100 metros, e foi desta forma que a Escola Industrial de João Pessoa conseguiu o primeiro espaço para prática de Educação Física no novo prédio da Escola, sede atual.

A Educação Física como disciplina obrigatória, naquele momento, era amparada por Lei, "artigo 22 da LDB/1961 que dispunha sobre a obrigatoriedade da prática da Educação Física nos cursos primários e médios - ciclo ginasial e ciclo colegial" - o que não alterou a rotina da EIJP, pois esta obrigatoriedade já existia na escola, decretada por normas internas. Alguns depoimentos, entretanto, são contrários a essa idéia:

"Depois que a Educação Física entrou no currículo ela foi . quase como um respeito que tiveram a ela ... ela passou a ser mais solicitada. E, por exemplo, em reuniões aqui na escola, reuniões ... aqui também tinha o grêmio, os alunos se prontificavam a se organizar, a fazer as competições, a fazer um ... as festas, tudo isso. Foi ... melhorou bastante, todos nós ficamos sentindo, houve uma certa ... um certo entusiasmo da parte até dos professores"(Professora aposentada - 1).

De 1961 a 1967, a grade curricular da educação geral do curso de Estradas mostra a Educação Física como disciplina, com uma carga horária de 60 horas, embora, nos mapas de freqüência e aproveitamento dos alunos, a Educação Física só apareça como disciplina de educação geral a partir de 1964. Antes disso, aparece como uma prática educativa. 
Tabela 1 - Mapa de Freqüiência e Aproveitamento de 1964. Escola Industrial Coriolano de Medeiros - $1^{\text {a }}$ série - 1964. Disciplina: Educação Física (Acervo Geral do CEFET-PB).

Nome do aluno: Aulas dadas: $\quad$ Faltas: $\quad$ Notas mensais: Média

Tabela 2 - Grade Curricular de 1961 / 67. Escola Técnica Federal da Paraíba. Curso: Estradas. Educação Geral: Disciplinas (Acervo Geral do CEFET-PB)

\begin{tabular}{lr}
\hline Português & $210 \mathrm{ch}$ \\
Educacão Física & $60 \mathrm{ch}$ \\
\hline Matemática & $270 \mathrm{ch}$ \\
Física & $180 \mathrm{ch}$ \\
Química & $180 \mathrm{ch}$ \\
História & $60 \mathrm{ch}$ \\
Inglês & $60 \mathrm{ch}$ \\
Total & $1.020 \mathrm{carga}$ horária
\end{tabular}

$\mathrm{Na}$ década de 60, ingressaram outros professores para lecionar a Educação Física: o professor Irapuan Botto e a professora Blice Procópio.

Em 1964, assumiu a Direção da Escola Industrial Federal da Paraíba o professor Itapuan Botto Targino, que, segundo depoimento dos professores de Educação Física, atuantes na época, representou um momento de crescimento muito grande para a Escola, criando-se uma nova mentalidade e um novo rumo. A Educação Física foi, a partir daí, mais privilegiada com espaço físico: foram construídas quadra externa, pista de atletismo, campo de futebol, banheiros coletivos, como também foram adquiridos materiais técnicopedagógicos para prática de esporte e aulas de Educação Física.

"Olhe, a Educação Física tinha o seu espaço principalmente na época de Itapuan Botto" (Professora aposentada - 1).

"Com a boa vontade do Dr. Itapuan Botto Targino, que ele nunca nos faltou, com relação ao material, à instalação, ele sempre foi uma pessoa que nos deu sempre toda cobertura, nunca falhou" (Professor da ativa - 1).

"O colega Itapuan passou aqui 18 anos, 18 anos de trabalho, ministrou com muito ardor, com muito afeto, com muita dignidade, com muita honradez" (Professora aposentada - 2).

A clientela feminina, que até 1964 estava excluída do corpo discente da Escola Industrial Federal da Paraíba, passou a integrá-lo sob iniciativa administrativa do professor Itapuan Botto. 
Nesta década, foi marcante a relação da Educação Física com o setor médico da instituição. Esta relação tem sido de dependência histórica na Educação Física, quase sempre se aproveitando do prestígio da Medicina para se legitimar no contexto escolar. Com base em Soares (1990, p. 55).

... desde o século XIX até os nossos dias, citando apenas a história mais recente, este pensamento tem influenciado a Educação Física manifestando-se desde a formação de seus profissionais, o que é facilmente demonstrando pelo excessivo número de disciplinas biológicas nos currículos das escolas de Educação Física.

Alguns depoimentos dos professores confirmam esta afirmação, como se vê a seguir:

"Então, por várias vezes ocorreu ... várias vezes que alunos ... no exame médico e biométrico vem saber que era portador de determinada doença" (Professor aposentado - 2).

"E nós tínhamos uma coisa muito importante ... que nos dava assim segurança, quando estávamos assim dando aula, porque nós tínhamos o seguro ... o seguro, a assistência médica" (Professora aposentada - 1).

As aulas de Educação Física até, mais ou menos, 1966, antes das grandes construções no setor de Educação Física, eram de ginástica calistênica ${ }^{3}$, ginástica pelo método Francês e prática de esportes. A prática de esporte foi intensificando-se devido à participação da EIFP em jogos estaduais e nos jogos brasileiros do Ensino Industrial. Após essa data, as instalações físicas para a prática da Educação Física na EIFP foram melhorando, pois até então se resumiam, apenas, a um campo sem piso, anexo ao campo de futebol onde se praticavam esportes coletivos, como voleibol, basquete, e iniciava-se o handebol na Paraíba, trazido pelos professores Bráulio e Blice, após curso em São Paulo. Nessa época, os professores de Educação Física da escola fizeram estágios no sul, em São Paulo, Rio de Janeiro e até no exterior.

"Então começamos a ... a introduzir outros desportes, como o handebol mesmo. O handebol foi introduzido na Paraíba, é ... nós, fomos eu e professora Blice" (Professor aposentado -2).

Em setembro de 1968, a Escola Técnica Federal da Paraíba sediou os III Jogos Brasileiros do Ensino Industrial, evento de nível nacional, que contou com a participação de 14 Escolas Técnicas do país e atraiu a comunidade paraibana para apreciar a prática de esporte. A escola já possuía uma infra-estrutura adequada para a prática da Educação Física, o que, sem dúvida, ampliou as possibilidades do desenvolvimento de inúmeras atividades relacionadas a atividades físicas, artísticas e culturais.

$\mathrm{Na}$ década de 60, os conteúdos priorizavam o desenvolvimento físico e o equilíbrio psicológico e moral do aluno, ficando evidente uma prática de Educação Física intimamente relacionada às práticas corporais advindas do universo militar. Esta exaltação e apelo às atitudes e posturas cívicas, aos componentes eugênicos e higiênicos,

\footnotetext{
${ }^{3}$ A ginástica calistênica era executada primeiramente sem o uso de aparelhos, que através do exercitamento dos músculos buscava encontrar saúde, vigor, bem como forma e movimentos elegantes.
} 
desempenho da aptidão física e formação moral a fim de aniquilarem desvios de comportamento, sinalizavam nessa direção.

"Depois que passasse por mim, estes alunos tinham prazer de entregar aos meus colegas e não havia assim ato de indisciplina, de revolta, de maneira nenhuma. Aluno sempre foi disciplinado, sempre honrou a Escola e criou nele um orgulho, não só por amor a Escola, por amor ao Brasil" (Professor aposentado - 2).

O poder centralizava-se no Coordenador de Educação Física e a execução era destinada ao restante do corpo docente. Nesse período, percebe-se uma necessidade de se legitimarem, através da ordem, a disciplina e a organização. Algumas declarações confirmam esta idéia:

"Em Educação Física sempre a gente tava passando a mão na cabeça. Bráulio não, mas Bráulio era Coordenador. Sempre dava ... sempre tinha uma pessoa ... sempre havia um jeitinho da gente" (Professora aposentada - 2).

"Na verdade ... que eu fui Coordenador desde que cheguei na Escola, passei quase toda minha vida como Coordenador de Educação Física”(Professor aposentado - 2).

A Educação Física militarista correspondia às demandas para a formação do trabalhador, já que a padronização dos indivíduos, a ausência de conflitos, o respeito à hierarquia, a prática mecânica repetitiva e irrefletida dos movimentos caíam como luvas no processo de adestramento e disciplinamento do corpo. Concordo com Enguita (1991 apud GARIGLIO, 1997, p. 219), quando afirma:

Sabe-se que no serviço militar os jovens aprendem a ser "homem" embora fosse melhor dizer operários. Não há nada mais parecido com a organização do trabalho em cadeia de que uma formação militar práticando a "instrução" nem nada que se assemelhe tanto à hierarquia despótica do trabalho quanto a disciplina aberrante do exército.

Nesta década, a Educação Física torna-se uma disciplina importante, relacionada ao processo de aprendizagem profissional e, intimamente, associada à possibilidade de melhoria da performance no trabalho, principalmente, pelo seu decantado poder de atuar sobre a saúde das pessoas. Assim segue o relato de um professor:

"Nós sentimos que determinados alunos até mesmo na prática no ... no seu trabalho de torno, como técnico, a Educação Física também ... sempre ... nós procurávamos orientar o aluno na ... que ... no sentido que ele pudesse ... é ... usar a Educação Física para que ele tivesse mais facilidade de manejar as suas máquinas" (Professor aposentado - 2). 


\section{INFLUÊNCIA DOS ESPORTES NA EDUCAÇÃO FÍSICA DA DÉCADA DE 70 NA} ETFPB

Na década de 70, os fatores políticos, o regime autoritário e centralizador instalado na Brasil e radicalizado no início da década de 70, aliados à política educacional estruturada pela Lei 5692 / 71, com seu ideário tecnicista, ampliam as conquistas da Educação Física dentro da Escola Técnica. É nessa década que se inicia a criação dos cursos técnicos e extinção do Ginásio Industrial, $1^{\circ}$ ciclo, que acaba em 1974. Antes, porém, no dia $1^{\circ}$ de maio de 1971, fora inaugurado o ginásio de esportes da Escola.

Em 1975, a Lei 6.251 / 75, definiu os objetivos da política nacional de Educação Física e Desporto: "aprimoramento da aptidão física da população, elevação do nível dos desportos de massa, difusão do desporto como forma de utilização do tempo de lazer, elevação do nível técnico esportivo das representações nacionais" (BETTI, 1991, p. 72). $\mathrm{Na}$ ETFPB, ratificou-se esse apoio ao esporte com aumento de verbas para melhoria da infra-estrutura, aumento dos espaços destinados à atividade esportiva, materiais para sua prática e treinamento de professores.

Realiza-se a inauguração da praça de esportes. O setor de Educação Física passa a ter o apoio da Direção para todos os eventos, é dado um grande incentivo para que a ETFPB seja vitoriosa em suas participações em jogos municipais e inter-estaduais. Houve uma adesão da Educação Física da ETFPB ao projeto político-educacional do governo. Seguem algumas falas dos professores:

"Que antigamente a gente tinha ... tinha realmente um grande apoio da Diretor, né? que era o professor Itapuan, que cobrava muito e a gente trabalhava com seriedade, com muito entusiasmo, muita vibração, que ele também contribuía para isso". (Professor da ativa -1$)$.

"Com ... à medida que a Escola passou a ser divulgada nos jogos, nas competições, nós fomos campeões nos jogos escolares" (Professor aposentado - 2).

Nessa época, a Educação Física ganhou legitimidade social ao assumir e submeter sua prática pedagógica aos códigos esportivos. Em conseqüência, era difícil diferenciar o esporte e o ensino do esporte na escola, com quase total submissão do esporte escolar aos códigos da instituição esportiva. Assim, o ensino do esporte ficava: "centrado quase que exclusivamente nos elementos técnicos-táticos do aprendizado e nas pré-condições fisiológicas e neuro-motoras para a prática de determinado esporte" (BRACH, 1992, p. 29).

A Coordenação de Educação Física começou a organizar, então, de forma mais efetiva, as suas equipes esportivas através de treinamentos extraclasse. Essas equipes eram treinadas pelos próprios professores da Coordenação e tinham o objetivo de representar a Escola em diversas competições no município, no Estado e fora dele. Existia uma expectativa de descobrir valores para o desporte de elite nacional. Como diz Silva (1994, p. 60):

Na década de 70, a conjuntura político-econômica, o sucesso do futebol na copa do México, contribuíram decisivamente para a associação entre o conceito de esporte e Educação Física no 
Brasil, visão essa que se disseminou na prática da Educação Física escolar.

Veja a seguir, o quadro de professores no ano de 1974 e o programa da Educação Física do ano de 1977, composto de conteúdos exclusivamente esportivos.

Tabela 3 - Professores / Coordenação de Educação Física (COEF)

\begin{tabular}{l}
\hline IRAPUAN BOTTO TARGINO - CHEFE DO SETOR \\
BRÁULIO DOS SANTOS PINTO \\
RUBENITA DE PÁDUA DO VALE \\
BLICE DE ANDRADE \\
JOSÉ GABÍNIO \\
JOAQUIM TINICO \\
OBS: A CONTRATAR: TÉCNICO DE HANDEBOL E TÉCNICO DE \\
FUTEBOL DE SALÃO
\end{tabular}

Tabela 4 - Programa de Educação Física / 1977. Carga horária: 90 horas (3 horas semanais) Série: $3^{\text {a }}$ (masculino). Fonte da COEF (as aulas eram ministradas através do método "Ginástico Desportivo Generalizado")

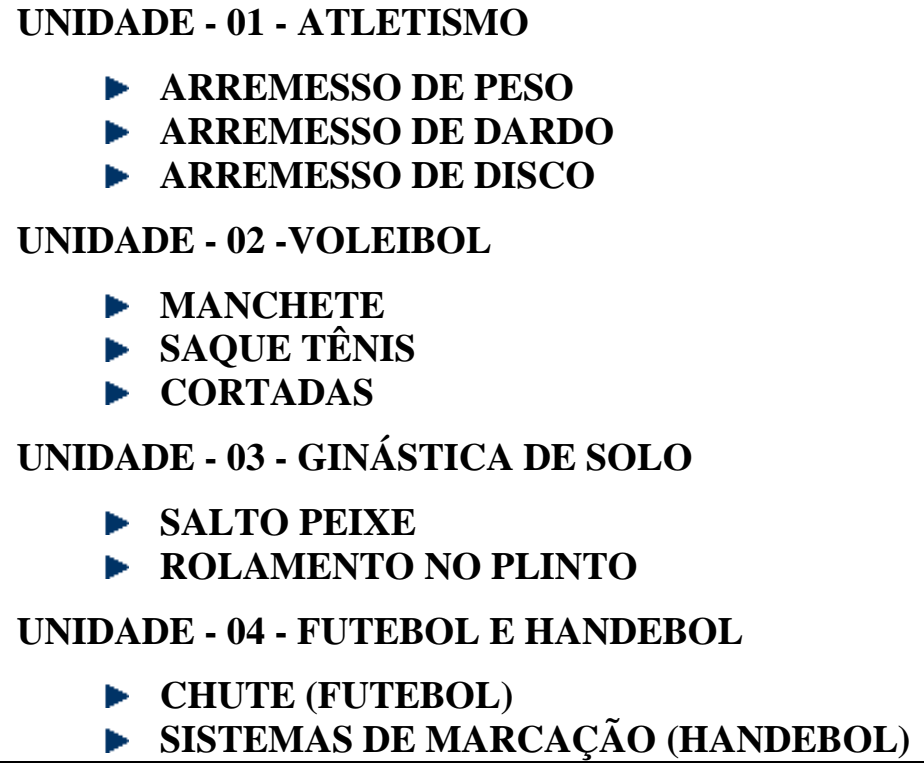

Na busca de ampliação de território no currículo, a Educação Física desenvolveu o conteúdo esporte como forma de mostrar à comunidade escolar a eficiência de seu trabalho e a sua importância para a formação dos alunos e, como marketing, para a melhoria da imagem da ETFPB na sociedade. A seguir depoimentos dos professores que atuaram na década de 70 na ETFPB:

"Todos aqueles que faziam parte da Escola naquela época, cada um tinha a sua missão, professor Gabínio do voleibol ... nós tínhamos. A escola sofria ... na verdade era um momento de crescimento com todos esses setores, e não só ela tinha prestígio 
dentro do seu ambiente escolar, como também lá fora na sociedade" (Professor aposentado - 2).

"Eram os jogos entre Escolas Técnicas, então o pessoal empolgado em viajar . prá competir ... lá fora. E realmente a correria aqui era grande para ver quem conseguiu o melhor, o melhor índice" (Professor da ativa - 1).

A Educação Física foi fortemente influenciada pela política educacional do regime militar através do Decreto no 69.450 / 71. Com os militares no poder, a Educação Física, tida historicamente como uma disciplina inferiorizada na escola, ganha, repentina e autoritariamente, um status de que, até então, não se tinha notícia. A Educação Física torna-se obrigatória nos três níveis de ensino.

Além da obrigatoriedade imposta, o Decreto citado acima determinava também diretrizes para a prática da Educação Física na escola, sugerindo conteúdos, metodologias, forma de planejamento e avaliação. Assim, era colocado como pressuposto básico, para o ensino da Educação Física, o desenvolvimento da aptidão física, que constitui, conforme o mesmo Decreto, "a referência fundamental para orientar o planejamento, controle e avaliação da Educação Física, desportiva e recreativa, no nível dos estabelecimentos de ensino”.

O currículo da ETFPB na década de 70 apoiava-se na pedagogia tecnicista:

... na pedagogia tecnicista era propício para o convívio de experiências pedagógicas que reforçassem a questão de que o sucesso era decorrente de esforço próprio, da competitividade, da competência técnica, do rendimento, da disciplina (RESENDE; SOARES, 1996, p. 53).

Os conteúdos das aulas de Educação Física eram distintos para meninos e meninas. A diferença ligava-se à forma de organização dos professores em homens e mulheres. As alunas só tinham aula com as professoras e para os meninos eram designados professores. As meninas tinham o mesmo número de aulas que os meninos e eram submetidas ao mesmo teste de aptidão que os meninos. Além de se submeterem a esses testes físicos, elas também se sujeitavam às mesmas normas rígidas de cumprimento do horário e do uso do uniforme. A Escola tinha duas professoras, Blice Procópio, que entrou em 1964 e Rubenita de Pádua, em 1970, esta através de concurso público. Eis a fala que comprova essa separação:

"Primeiro a nossa, a nossa filosofia de Educação Física, né? era as professoras só da parte feminina, não é? do feminino, porque era separado o masculino do feminino" (Professora aposentada 2).

A Educação Física da ETFPB já abordava, nessa época, o desenvolvimento da aptidão física. Eram utilizados testes para avaliação das qualidades físicas, que também faziam parte dos conteúdos das aulas, como se pode ver no programa de 1978 a 1980. 
Tabela 5 - Programa de Educação Física de 1978 / 80. Disciplina: Educação Física. Carga horária: 90 horas (3 horas semanais). Série: $1^{\circ}$ (Feminino). Fonte COEF UNIDADE 1 - CONDICIONAMENTO BÁSICO PARA TREINAMENTO FÍSICO - COORDENAÇÃO

EQUILÍBRIO

FLEXIBILIDADE

D ELASTICIDADE

RESISTÊNCIA

- FORÇA

UNIDADE 2 - ATLETISMO

UNIDADE 3 - VOLEIBOL

UNIDADE 4 - GINÁSTICA RÍTMICA DESPORTIVA

A turma masculina, também da $1^{\text {a }}$ série, tinha algumas diferenças mínimas. Existia uma exigência maior no treinamento básico e nas unidades seguintes, que eram as mesmas, com exceção da ginástica de solo, no lugar da ginástica rítmica das meninas (ver Tabela 2.6). Os alunos tinham uma aula mais intensa, ou seja, no atletismo faziam corrida de fundo, enquanto as meninas faziam corrida de revezamento e meio fundo.

Havia, então, uma sintonia entre o projeto do MEC para a Educação Física e a proposta de Educação Física da ETFPB, tanto por ser uma instituição federal, quanto por ser uma escola profissionalizante voltada para a formação de mão-de-obra.

Segundo Bracht (1992, p. 23) essas práticas pedagógicas se baseavam, no dizer de um educador da época, em alguns dos pressupostos do tecnicismo:

... é marcado pelos objetivos operacionais do primado do planejamento, da tecnologia do ensino. Menos o professor e o aluno têm importância no processo de ensino, e mais o planejamento. Sob essa orientação ocorreu reducionismo (...) pela necessidade de operacionalizar os objetivos, o que levou, pelo menos na tendência, à substituição do lúdico em favor de tarefas mecânicas.

Veja-se a fala de alguns professores, que atuaram na década de 70 na ETFPB, a respeito dos objetivos da Educação Física.

"Visava o aprimoramento fisiológico do aluno" (Prof a aposentada $-1)$.

“É, temos um programa de ... de avaliação, de verificação, que era feito no campo de futebol com o objetivo da gente descobrir os valores" (Professor da ativa - 1).

"Não, os objetivos eram aqueles de preparar física ... físicamente o homem. Psicológico e físico, dando ao aluno uma condição melhor dele se conduzir na vida, é ... na vida, no decorrer da sua vida, é claro. Então foi introduzido o esporte, criando uma 
mentalidade mais ... no aluno da Escola Técnica, uma mentalidade mais evoluída, mais disciplina, mais ordem, na verdade" (Professor aposentado - 2).

Os documentos curriculares, encontrados na pesquisa, mostram que a Educação Física deixa de ser uma prática pedagógica no currículo dos cursos técnicos da ETFPB no ano de 1973, para fazer parte das disciplinas do núcleo comum.

Tabela 6 - Documento Curricular de 1972. Fonte: Acervo Geral do CEFET-PB.

\begin{tabular}{llccccc}
\hline III - PRÁTICA EDUCATIVA & & & & & \\
1 - EDUCAÇÃO FÍSICA & 3 & 3 & & 3 & & 270 \\
TOTAL PARCIAL & 3 & 3 & & 3 & & 270 \\
TOTAL GERAL DE TODAS AS DISCIPLINAS & 33 & 33 & 33 & 3030 \\
\hline
\end{tabular}

Tabela 7 - Documento Curricular de 1973. Fonte: Acervo Geral do CEFET-PB.

I - DISCIPLINAS DO NÚCLEO COMUM

1 - COMUNICAÇÃO E EXPRESSÃO

2 - INGLÊS

3 - EDUCACÃO FÍSICA - 3 AULAS SEMANAIS NA $1^{\mathrm{a}}, 2^{\mathrm{a}}$ E $3^{\mathrm{a}}$ SÉRIE DO $2^{\circ}$ GRAU - TOTAL DE HORAS 270

A Coordenação de Educação Física, até os dias de hoje, comprova através do seu ambiente a importância do esporte, enquanto componente imprescindível à perpetuação da disciplina no currículo. Mas a idéia de um corpo saudável para o trabalho não poderia ser colocada de lado, pois o esporte estava mais relacionado a objetivos ligados ao desenvolvimento da competição, espírito de equipe, ao condicionamento a regras preestabelecidas do que, propriamente, à questão da saúde. Para isso, era necessário que, paralelo ao incentivo dado ao esporte, a idéia da Educação Física, ligada à melhoria da saúde dos alunos se fizesse presente no planejamento anual.

\section{REFERÊNCIAS}

1. BETTI, M. Perspectivas para Educação Física Escolar. Revista Paulista de Educação Física. São Paulo, v.5, n. 1, 2, p. $70-75,1991$.

2. BRACH, W. Educação Física e Aprendizagem Social. Porto Alegre: Magíster, 1992. p. 29.

3. CAStellani, L. Política educacional e Educação Física. Campinas: Autores Associados, 1998.

4. GARIGLIO. M. J. Ensino da Educação Física nas Engrenagens de uma Escola Profissionalizante. Dissertação de Mestrado (Mestrado em Educação). Universidade Federal de Minas Gerais, Brasil. 1997. 269 p.

5. GOMES, M. J. A Educação Física no novo modelo do Ensino Técnico. Dissertação de Mestrado (Mestrado em Educação). Universidade Federal da Paraíba, Brasil. 2000. 
6. GOMES, M. J. (2005). Hábitos de Actividad Física y Salud en estudiantes de la Enseñanza Técnica del CEFET de Paraíba. Tese Doutoral (Doutorado em Atividade Física e Saúde). Universidade de Granada (UGR), Espanha. 2005. 454p.

7. RESENDE, H.; SOARES, A. Conhecimento e Especificidade da Educação Física Escolar, na Perspectiva da Cultura Corporal. In: Revista paulista de Educação Física. São Paulo. n², p. 49 a 59, 1996.

8. SILVA, S. Educação Física: Um Fenômeno que se Desvela. In: Revista paulista de Educação Física. São Paulo, v. 8, n.1, p. 58 a 68, jan/jun, 1994.

9. SOARES, C. Fundamentos da Educação Física Escolar. In: Revista brasileira de Estudos Pedagógicos. Brasília, v.71, n.167, p.51-67, 1990.

10. SOARES, C. Educação Física Escolar: Conhecimento e Especificidade. In: Revista Paulista de Educação Física, São Paulo, 2, p.6-12, 1996. 